\title{
Coupling Reaction of Two Kinds of Molecular-Weight Controlled Biodegradable Polymers
}

\author{
Jin ZhOU, Aiko Kaga, Akinori TAKasu, Yoshihito InAI, \\ and Tadamichi HIRABAYASHI ${ }^{\dagger}$ \\ Department of Environmental Technology and Urban Planning, Graduate School of Engineering, \\ Nagoya Institute of Technology, Gokiso-cho, Showa-ku, Nagoya 466-8555, Japan
}

(Received April 10, 2003; Accepted August 5, 2003)

\begin{abstract}
Poly( $\varepsilon$-caprolactone) (PCL) having controlled molecular weight was synthesized by ring opening polymerization of $\varepsilon$-caprolactone (CL) initiated by ethanol with stannous(II) octanoate or scandium(III) trifluoromethane sulfonate as a catalyst. The hydroxyl end group of the resulting polymer was converted to trimethylsiloxyl group by using hexamethyldisilazane. On the other hand, poly(vinyloxy-t-butyldimethylsilane) (PVOTBDMS) was obtained by aldoltype of group transfer polymerization. Under the presence of $\mathrm{ZnBr}_{2}$ or $\mathrm{TiCl}_{4}$ as the catalyst, the coupling reaction of above two precursor polymers was carried out so as to build PCL-block-PVOTBDMS with controlled molecular weight and narrow molecular weight distribution. The PCL-block-PVA as the final goal could be obtained by elimination of the silyl groups in the above block copolymer.

KEY WORDS Biodegradable Copolymer / Block Copolymer / Aldol-GTP / Poly(vinyloxy-tbutyldimethylsilane) / Poly( $\varepsilon$-caprolactone) / Living Ring-Opening Polymerization /
\end{abstract}

In recent years, biodegradable polymers have attracted more and more attention from many fields to replace the traditional polymers owing to the increasing environmental problems caused by polymer disposal after use. It has been reported that they can be efficiently degraded into non-toxic water-soluble oligomers by a great number of living cells or microorganisms widely inhabited in the natural environment, then the water-soluble oligomers can be reutilized in many ways and finally changed into water, carbon dioxide or methane through several metabolic procedures of microorganisms. ${ }^{1-5}$ It is well known that aliphatic polyesters are the most promising class of biodegradable materials which can be prepared by biosynthesis and chemical process ${ }^{6-8}$ such as polycondensation and ring-opening polymerization.

Poly( $\varepsilon$-caprolactone) (PCL) is one of the wellstudied aliphatic polyesters, which can be easily synthesized by CL with ethanol as an initiator and stannous(II) octanoate $\left(\mathrm{Sn}(\mathrm{Oct})_{2}\right)$ as a catalyst. ${ }^{9-11} \mathrm{Up}$ to present, $\mathrm{Sn}(\mathrm{Oct})_{2}$ and aluminum triisopropoxide $\left(\mathrm{Al}(\mathrm{O} i-\mathrm{Pr})_{3}\right)$ have been most conventional catalysts for the ring-opening polymerization of lactones. ${ }^{10,12} \mathrm{Re}$ cently Kobayashi et al. insisted that rare earth metal triflates such as $\mathrm{Sc}(\mathrm{OTf})_{3}$ can be used as an intriguing Lewis acid catalyst in organic synthesis. ${ }^{13}$ Successful ring-opening polymerization (ROP) of CL using $\mathrm{Sc}(\mathrm{OTf})_{3}$ was firstly reported by Nomura et al., showing the formation of PCL with very narrow molecular distribution even at $25^{\circ} \mathrm{C} .{ }^{14}$ Furthermore $\mathrm{Sc}(\mathrm{OTf})_{3}$ as

${ }^{\dagger}$ To whom correspondence should be addressed. well as $\operatorname{Sn}(\mathrm{OTf})_{2}$ was proved to be effective toward the ROP of other lactones, including $\beta$-butyrolactone, $\alpha$-allyl(valerolactone) and so on. ${ }^{15,16}$ Polymerization of these monomers proceeded in living manner and gave the polymers with controlled molecular weights and narrow molecular weight distributions. It was reported that the semicrystalline PCL can be degraded in many different environments such as soil, river water etc. ${ }^{17}$ Especially it can be degraded within a very short time by using of suitable lipases. ${ }^{18}$ Irrespective of its excellent biodegradability, however, PCL is obviously limited in daily use because of its low melting point $\left(60^{\circ} \mathrm{C}\right)$. In order to satisfy wide needs in the field of industry, it would be very desirable to tie up the excellent biodegradability of polyesters and the favorable physical properties of other polymers. Many PCL-containing biodegradable copolymers have been tried to synthesize in different ways. Making PCL-containing block copolymer is one of the potential methods for this purpose.

On the molecular architecture of the block copolymers, designing of chemical composition of the copolymer and the block length must be important to produce materials with a wide range of properties. Poly(vinyl alcohol) (PVA) is one of the water-soluble polymers and the only one vinyl-type polymer of which biodegradability has been confirmed, although its biodegradation rate under natural environmental conditions is not rapid enough to classify as an practical biodegradable polymer. ${ }^{19}$ PVA is often blended with other biodegradable polymers such as PCL to adjust 

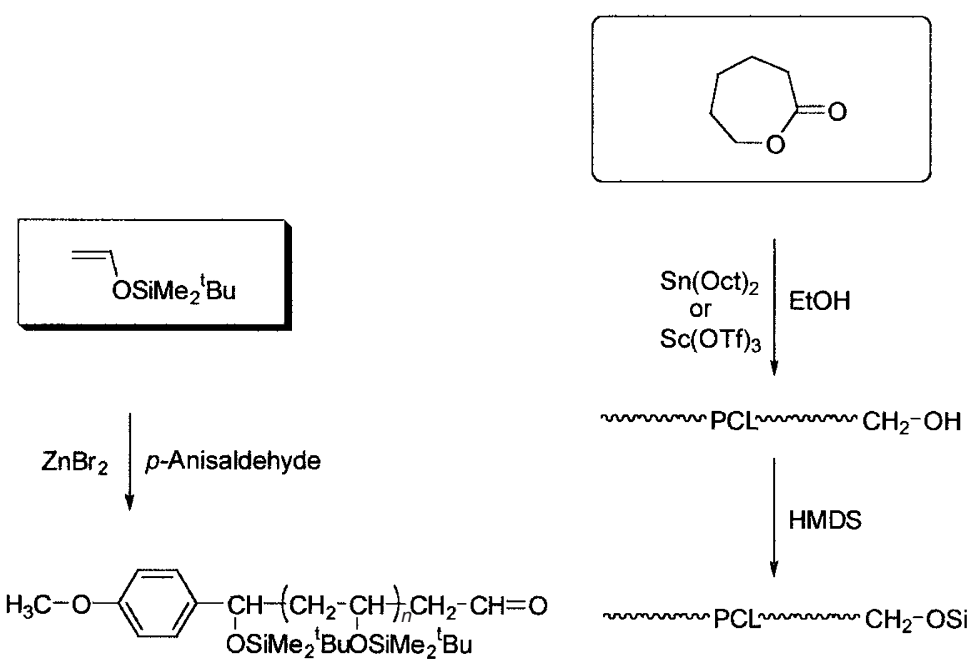

$\mathrm{OSiMe}_{2}{ }^{\mathrm{T}} \mathrm{BuOSiMe}{ }_{2}{ }^{\mathrm{B} u}$

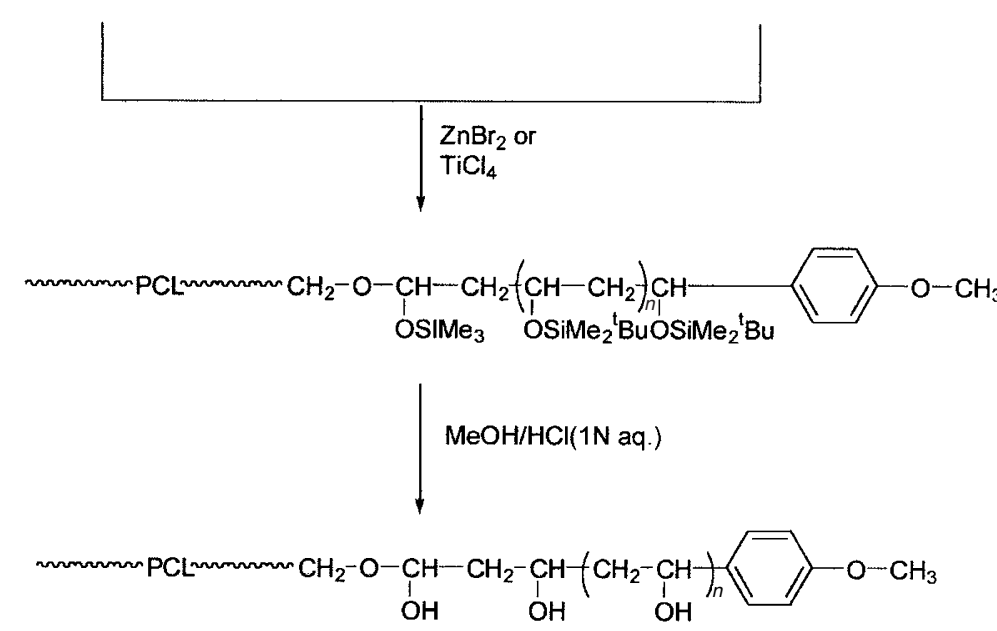

Scheme 1. The synthesis route to PCL-block-PVA.

hydrophobic/hydrophilic properties of the final materials. $^{20}$

Here we exerted ourselves for synthesis of a novel biodegradable hydrophobic-hydrophilic block copolymer, PCL-block-PVA, with well-defined molecular weight by way of an approach route involving living ring-opening polymerization of caprolactone and Aldol-GTP ${ }^{21}$ of vinyl silyl ether for PVA unit.

In this article, at first $\mathrm{Sn}(\mathrm{Oct})_{2}$ and $\mathrm{Sc}(\mathrm{OTf})_{3}$ were examined as the catalyst for the living ringopening polymerization of CL. Next the hydroxyl end group of PCL was converted into trimethylsilyloxyl group and then this end-capped PCL was coupled with poly(vinyloxyl-tert-butyldimethylsilane) (PVOTBDMS) under the presence of $\mathrm{ZnBr}_{2}$ or $\mathrm{TiCl}_{4}$ catalyst, as described in Scheme 1. PVOTBDMS could be prepared by Aldol-GTP of the corresponding monomer. Finally elimination of the trialkylsilyl groups from the coupled copolymer resulted in formation of PCL-block-PVA. It is expected that the biodegradability, solubility in organic solvents, thermal property, and other characters of these block copolymers can be controlled by changing length of PCL- and
PVA-chain.

\section{EXPERIMENTAL}

\section{Materials}

$\varepsilon$-Caprolactone (CL) was dried over $\mathrm{CaH}_{2}$ for $24 \mathrm{~h}$ and distilled under reduced pressure just before use. Scandium (III) trifluoromethane sulfonate $\left(\mathrm{Sc}(\mathrm{OTf})_{3}\right)$ was dried in vacuo, used as solution in toluene/tetrahydrofuran (THF) (80/20) mixture. Stannous (II) octanoate $\left(\mathrm{Sn}(\mathrm{Oct})_{2}\right)$ and titanium (IV) chloride $\left(\mathrm{TiCl}_{4}\right)$ (Aldrich, $0.1 \mathrm{~mol} \mathrm{~L}^{-1}$ in toluene) were used as received. Ethanol was distilled after reflux with $\mathrm{MgI}_{2} /$ methanol. Hexamethyldisilazane (HMDS) was used without further purification. $p$-Anisaldehyde was distilled from $\mathrm{CaH}_{2}$ under reduced pressure. $\mathrm{ZnBr}_{2}$ was purified by sublimation. Menthyl ethyl ether (MEE) was synthesized by Williamson method and purified by distillation.

\section{Measurement}

${ }^{1} \mathrm{H}$ nuclear magnetic resonance (NMR) and ${ }^{13} \mathrm{C}$ NMR were carried out with Bruker DPX200 
Table I. Living ring-opening polymerization of $\varepsilon$-CL initiated by ethanol

\begin{tabular}{cccrccccc}
\hline $\begin{array}{c}\text { Run } \\
\text { No }\end{array}$ & {$[M]_{0} /[I]_{0}$} & Cat. & $\begin{array}{c}\text { Tem. } \\
{ }^{\circ} \mathrm{C}\end{array}$ & $\begin{array}{c}\text { Time } \\
\mathrm{h}\end{array}$ & $\begin{array}{c}\text { Yield } \\
(\mathrm{wt} \%)\end{array}$ & $\mathrm{DPn}^{\mathrm{a}}$ & $\begin{array}{c}M_{\mathrm{n}}{ }^{\mathrm{b}} \\
\times 10^{-3}\end{array}$ & $M_{\mathrm{w}} / M_{\mathrm{n}}{ }^{\mathrm{c}}$ \\
\hline 1 & 20 & $\mathrm{Sn}(\mathrm{Oct})_{2}$ & 110 & 24 & 98.5 & 14 & 2.89 & 1.37 \\
2 & 20 & $\mathrm{Sn}(\mathrm{Oct})_{2}$ & 90 & 24 & 95.5 & 21 & 4.87 & 1.34 \\
3 & 20 & $\mathrm{Sc}(\mathrm{OTf})_{3}$ & 65 & 24 & 95.9 & 16 & 3.76 & 1.29 \\
4 & 30 & $\mathrm{Sc}(\mathrm{OTf})_{3}$ & 65 & 20 & 90.0 & 28 & 6.65 & 1.13 \\
5 & 100 & $\mathrm{Sn}(\mathrm{Oct})_{2}$ & 90 & 24 & 98.0 & 58 & 12.58 & 1.43 \\
\hline
\end{tabular}

${ }^{\text {a }}$ Degree of polymerization determined by ${ }^{1} \mathrm{H}$ NMR spectra in $\mathrm{CDCl}_{3}$ at room temperature. ${ }^{\mathrm{b}}$ Number-average molecular weight determined by SEC, calibrated by Polystyrene Standards. ${ }^{\mathrm{c}}$ Molecular weight distribution determined by SEC, calibrated by Polystyrene Standards.

$(200 \mathrm{MHz})$ or Varian GEMINI300 $(300 \mathrm{MHz})$ in $\mathrm{CDCl}_{3}$ at room temperature. Number-averaged molecular weight $\left(M_{\mathrm{n}}\right)$ and polydispersity index of the molecular weight $\left(M_{\mathrm{w}} / M_{\mathrm{n}}\right)$ were determined by size-exclusion chromatography (SEC) with the column system of Tosoh G2000-, G3000-, G4000-, and G5000-HXL, used THF as an eluent and calibrated with polystyrene standards. Infrared (IR) spectrum was recorded in $\mathrm{KBr}$ using a JASCO FT/IR-400 spectrometer.

\section{Synthesis of PCL}

A round-bottom flask with a magnetic stirring chip was flamed and filled with nitrogen atmosphere for three times. Ethanol as an initiator and a solution of catalyst $\mathrm{Sn}(\mathrm{Oct})_{2}$ or $\mathrm{Sc}(\mathrm{OTf})_{3}$ were charged in the flask, and then the proper amount of CL monomer according to the predetermined molar ratio to initiator was added, reacted at a constant temperature on an oil-bath. After the appropriate reaction time, the polymer was precipitated in $n$-hexane and dried in vacuo up to a constant weight.

\section{Chemical Modification of the End-Group of PCL}

Hexamethyldisilazane in toluene $(2.0 \mathrm{wt} \%)$ was added into toluene solution of PCL and subject to react on the oil-bath at $80^{\circ} \mathrm{C}$ for $160 \mathrm{~h}$. The product polymer (PCL-OTMS) was reprecipitated in $n$-hexane and dried in vacuo.

\section{Synthesis of Vinyloxyl-tert-Butyldimethylsilane (VOTB-} $D M S)^{22}$

THF $(200 \mathrm{~mL})$ was placed in a three-necked $500 \mathrm{~mL}$ flask, which was equipped with a dropping funnel and a nitrogen gas inlet and preliminarily flame-dried and purged by $\mathrm{N}_{2}$. Then $n$-BuLi was added to the flask cooled on an ice-bath through the dropping funnel under nitrogen atmosphere. The solution was kept magnetically stirring for $24 \mathrm{~h}$. After the reaction mixture was condensed partly, tert-butyldimethylchlorosilane solution in THF was added and stirred for $15 \mathrm{~h}$. The solvent and monomer were collected by the trap-to-trap method. The solution was evaporated under reduced pressure so as to remove the monomer completely.

\section{Aldol-type of Group Transfer Polymerization (Aldol- GTP) of VOTBDMS ${ }^{21}$}

A flame-dried and $\mathrm{N}_{2}$-purged flask with a stirrer chip was charged with the calculated amounts of VOTBDMS (monomer), $p$-anisaldehyde (initiator), and solvent, then was cooled on an ice-bath. In order to keep the reaction proceeding in a homogeneous environment, $\mathrm{ZnBr}_{2}$ (catalyst) was added as ether solution prepared in advance. The reaction was stopped by adding of a large excess of methanol-triethylamine $(1: 1 \mathrm{vol})$ to the initiator after a predetermined period. The reaction mixture was poured into methanol and the precipitate was dried in vacuo up to a constant weight.

\section{Coupling Reaction of PVOTBDMS with PCL-OTMS}

The flame-dried and $\mathrm{N}_{2}$-purged glass tube was charged with PVOTBDMS dissolved in toluene under a dry nitrogen atmosphere. The calculated amount of $\mathrm{ZnBr}_{2}$ in diethyl ether or $\mathrm{TiCl}_{4}$ in toluene was added and stirred for $1 \mathrm{~h}$ at room temperature. The solution of PCL-OTMS in toluene was then added into the mixture and subject to react for $150 \mathrm{~h}$ at $60^{\circ} \mathrm{C}$ on an oil bath. The polymer was collected by reprecipitation from toluene solution into $n$-hexane and dried in vacuo.

\section{RESULTS AND DISCUSSION}

\section{Synthesis of PCL}

It has been known in the ring-opening polymerization of lactone monomers catalyzed by $\mathrm{Sn}(\mathrm{Oct})_{2}$ that the molecular weights of the polymers could be controlled by the monomer/initiator molar ratios. ${ }^{23}$ On the other hand, some intermolecular and intramolecular transesterification was pointed out to be occurred at the elevated temperature which is necessary to activate the catalyst $\mathrm{Sn}(\mathrm{Oct})_{2} .{ }^{24}$ Therefore we also employed $\mathrm{Sc}(\mathrm{OTf})_{3}$ referred in introduction. Polymerization of 
Table II. Modified reaction of OH end group of PCL by hexamethyldisilazane ${ }^{\mathrm{a}}$

\begin{tabular}{ccccccr}
\hline $\begin{array}{c}\text { Run } \\
\text { No }\end{array}$ & $\begin{array}{c}M_{\mathrm{n}}{ }^{\mathrm{b}} \\
\times 10^{-3}\end{array}$ & $\begin{array}{c}\text { Yield } \\
(\mathrm{wt} \%)\end{array}$ & $\begin{array}{c}\text { Degree of Masking } \\
\%\end{array}$ & $\begin{array}{c}M_{\mathrm{n}}{ }^{\mathrm{c}} \\
\times 10^{-3}\end{array}$ & $M_{\mathrm{w}} / M_{\mathrm{n}}{ }^{\mathrm{d}}$ & $\mathrm{DPn}^{\mathrm{e}}$ \\
\hline $1^{\mathrm{f}}$ & 2.89 & 83.0 & 100.0 & 3.55 & 1.26 & 22 \\
2 & 3.76 & 77.6 & 96.5 & 2.40 & 1.29 & 8 \\
3 & 4.84 & 88.1 & 99.7 & 6.04 & 1.34 & 23 \\
4 & 6.65 & 91.9 & 100.0 & 7.02 & 1.13 & 36 \\
5 & 12.58 & 86.0 & 100.0 & 13.43 & 1.44 & 62 \\
\hline
\end{tabular}

${ }^{\mathrm{a}}$ Use Toluene as solvent, Tem. $=80^{\circ} \mathrm{C}$, Time $=160 \mathrm{~h} .{ }^{\mathrm{b}}$ Number-average molecular weight of PCL before modified reaction, determined by SEC, calibrated by Polystyrene Standards. ${ }^{\mathrm{c}}$ Number-average molecular weight of PCL after modified reaction, determined by SEC, calibrated by Polystyrene Standards. ${ }^{\mathrm{d}}$ Molecular weight distribution of PCL after modified reaction, determined by SEC, calibrated by Polystyrene Standards. ${ }^{e}$ Degree of Polymerization of $\mathrm{PCL}$ after modified reaction, determined by ${ }^{1} \mathrm{H}$ NMR. ${ }^{\mathrm{f}}$ Reaction time $=120 \mathrm{~h}$.

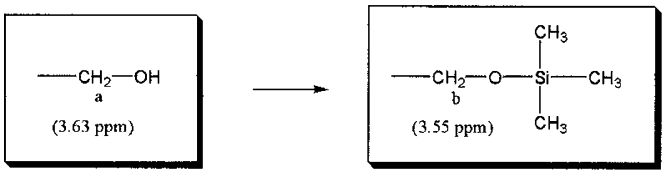

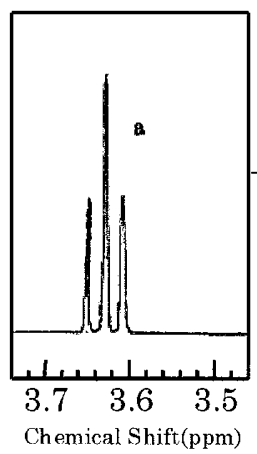

$0 \mathrm{~h}$

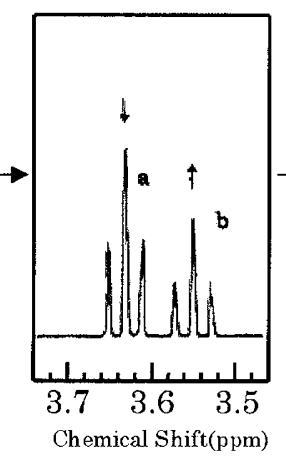

$48 \mathrm{~h}$

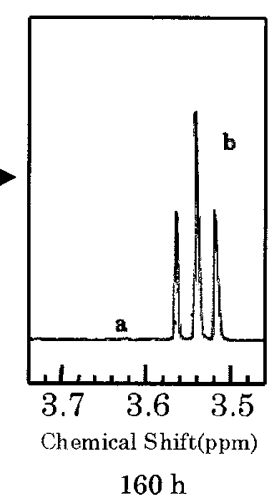

$160 \mathrm{~h}$
Figure 1. Monitoring of the chemical shift of $\mathrm{CH}_{2}$ proton adjacent to end group of PCL during the chemical modification of end group of PCL by HMDS.

CL carried out in this work was summarized in Table I. The formation of PCL with hydroxyl end group was mainly confirmed by ${ }^{1} \mathrm{HNMR}$.

\section{Chemical Modification of Hydroxyl End Group of PCL}

Hexamethyldisilazane (HMDS) was employed to mask the hydroxyl group at the terminal of PCL-chain without formation of $\mathrm{HCl}$ as contrasted with $\mathrm{Me}_{3} \mathrm{SiCl}$. In the ${ }^{1} \mathrm{H}$ NMR spectrum showed as Figure 1, the terminal methylene proton $\left(-\mathrm{CH}_{2} \mathrm{OH}\right)$ signal at $3.63 \mathrm{ppm}$ faded out with the passage of time and a new methylene signal at $3.55 \mathrm{ppm}$ assignable to $-\mathrm{CH}_{2} \mathrm{OSi}\left(\mathrm{CH}_{3}\right)_{3}$ appeared, indicating that the hydroxyl end group of PCL can be modified by HMDS.

The degree of masking was calculated from the signal intensity ratio of methyl proton $\left(\mathrm{CH}_{3}\right)_{3} \mathrm{Si}-$ and the total terminal methylene proton. It is worthwhile to noting that the speed of masking tended to decrease with increasing chain length of PCL, even though the degree

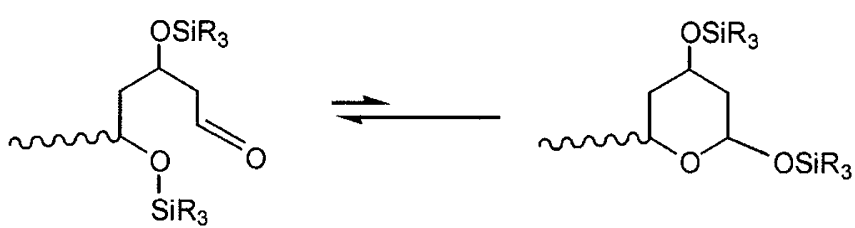

Scheme 2. Loss of formyl group by back-biting at the terminal of PVOTRS.

of masking can be finally attained almost $100 \%$. This suggested that the hydroxyl end group would be partly buried inside of the polymer matrix and made the speed of modification for longer-chain PCL somewhat slow. For long-chain PCL, longer reaction time was necessary to complete the modification of the end group. For the shorter-chain PCL sample, however, lowering the yield and the decrease of molecular weight were observed for the samples obtained after such a long reaction time(Run 2 in Table II). These behaviors would be interpreted by the term of back-biting (depolymerization). To the contrary, no distinguished decrease in yield and $M_{\mathrm{n}}$ was appeared under same reaction time for longer-chain PCL.

\section{Aldol-GTP of VOTBDMS}

Aldol-GTP ${ }^{21}$ of VOTBDMS was initiated from $p$ anisaldehyde with $\mathrm{ZnBr}_{2}$ catalyst dissolved in ether to keep the reaction system homogeneous. Molecular weight data in Table III demonstrated the good living character. The formyl group at the terminal $\left(-\mathrm{CH}_{2} \mathrm{CH}=\mathrm{O}\right)$ could be confirmed by the signal at $9.70 \mathrm{ppm}$ in the ${ }^{1} \mathrm{HNMR}$ spectrum, though the intensity was somewhat less than the theoretical value due to back-biting reaction during polymerization (Scheme 2).

\section{Coupling Reaction of PVOTBDMS and PCL-OTMS}

The coupling reaction of PVOTBDMS and PCLOTMS was carried out in the presence of $\mathrm{ZnBr}_{2}$ or $\mathrm{TiCl}_{4}$ as a catalyst. In order to obtain block copolymers composed of different chain length, PCL-OTMS 
Table III. Aldol-GTP of VOTBDMS in toluene

\begin{tabular}{cccccccc}
\hline Run & Catalyst $^{\mathrm{a}}$ & {$[M]_{0} /[I]_{0}$} & $\begin{array}{c}\text { Temp. } \\
{ }^{\circ} \mathrm{C}\end{array}$ & $\begin{array}{c}\text { Time } \\
\mathrm{h}\end{array}$ & $\begin{array}{c}\text { Yield } \\
(\mathrm{wt} \%)\end{array}$ & $\begin{array}{c}M_{\mathrm{n}}{ }^{\mathrm{d}} \\
\times 10^{-3}\end{array}$ & $M_{\mathrm{w}} / M_{\mathrm{n}}{ }^{\mathrm{d}}$ \\
\hline 1 & $\mathrm{ZnBr}_{2}-\mathrm{Et}_{2} \mathrm{O}$ & 10 & 0 & 48 & 66.3 & 1.49 & 1.32 \\
2 & $\mathrm{ZnBr}_{2}-\mathrm{Et}_{2} \mathrm{O}$ & 10 & 0 & 48 & 72.0 & 2.10 & 1.49 \\
3 & $\mathrm{ZnBr}_{2}-\mathrm{Et}_{2} \mathrm{O}$ & 40 & 0 & 90 & 64.7 & 3.42 & 1.43 \\
4 & $\mathrm{ZnBr}_{2}-\mathrm{MEE}^{\mathrm{b}}$ & 50 & 0 & 135 & 84.4 & 6.74 & 1.70 \\
$5^{\mathrm{c}}$ & $\mathrm{ZnBr}_{2}-\mathrm{MEE}^{\mathrm{b}}$ & 50 & 0 & 163 & 89.5 & 6.83 & 1.90 \\
\hline
\end{tabular}

${ }^{\mathrm{a}}\left[\mathrm{Et}_{2} \mathrm{O}\right] /\left[\mathrm{ZnBr}_{2}\right]=5.0$ (Run1-3); $[\mathrm{MEE}] /\left[\mathrm{ZnBr}_{2}\right]=6$ (Run4-5). ${ }^{\mathrm{b}} \mathrm{MEE}$ : Menthyl Ethyl Ether. ${ }^{\mathrm{c}}$ Use Toluene/MEE (vol.50/50) solvent mixture. ${ }^{\mathrm{d}}$ Number-average molecular weight and molecular weight distribution determined by SEC, calibrated by Polystyrene Standards.

Table IV. Coupling reaction of TMS modified PCL $\left(\mathrm{P}_{1}\right)$ and PVOTBDMS( $\left.\mathrm{P}_{2}\right)$ using $\mathrm{ZnBr}_{2}$ as catalyst in toluene $\left(\mathrm{Tem} .=60^{\circ} \mathrm{C}\right.$, Time $\left.=150 \mathrm{~h}\right)$

\begin{tabular}{|c|c|c|c|c|c|c|c|c|c|c|}
\hline \multirow{2}{*}{$\begin{array}{l}\text { Run } \\
\text { No. }{ }^{\text {a }}\end{array}$} & \multicolumn{2}{|c|}{$\mathrm{P}_{1}$} & \multicolumn{2}{|r|}{$\mathrm{P}_{2}$} & \multirow{2}{*}{$\begin{array}{c}{\left[\mathrm{ZnBr}_{2} /-\mathrm{OTMS}\right]^{\mathrm{c}}} \\
(\mathrm{mol} / \mathrm{mol})\end{array}$} & \multirow{2}{*}{$\begin{array}{l}\text { Yield }^{d} \\
\left(w t_{0}\right)\end{array}$} & \multirow{2}{*}{$\begin{array}{c}\mathrm{P}_{2} / \mathrm{P}_{1}{ }^{\mathrm{e}} \\
(\mathrm{mol} / \mathrm{mol})\end{array}$} & \multirow{2}{*}{$\begin{array}{c}\text { Block } \\
\text { copolymer }^{\mathrm{f}} \\
(\%)\end{array}$} & \multirow{2}{*}{$\begin{array}{l}M_{\mathrm{n}}^{\mathrm{b}} \\
\times 10^{-3}\end{array}$} & \multirow[b]{2}{*}{$M_{\mathrm{w}} / M_{\mathrm{n}} \mathrm{b}$} \\
\hline & $\overline{M_{\mathrm{n}}}{ }^{\mathrm{b}}$ & $\begin{array}{l}M_{\mathrm{w}} / M_{\mathrm{n}}^{\mathrm{b}} \\
10^{-3}\end{array}$ & $\overline{M_{\mathrm{n}}{ }^{\mathrm{b}}}$ & $\begin{array}{l}M_{\mathrm{w}} / M_{\mathrm{n}}^{\mathrm{b}} \\
<10^{-3}\end{array}$ & & & & & & \\
\hline 1 & 2.40 & 1.31 & & - & $1 / 2$ & 66.3 & - & - & 3.04 & 1.30 \\
\hline 2 & 6.04 & 1.27 & & - & $1 / 2$ & 93.1 & - & - & 6.10 & 1.29 \\
\hline 3 & 3.55 & 1.26 & 1.49 & 1.32 & - & 33.0 & - & - & - & - \\
\hline 4 & 3.55 & 1.26 & 1.49 & 1.32 & $1 / 10$ & 24.0 & - & - & - & - \\
\hline 5 & 3.55 & 1.26 & 1.49 & 1.32 & $1 / 3.5$ & 29.0 & $25.8 / 74.2$ & 100.0 & 6.20 & 1.53 \\
\hline 6 & 6.04 & 1.27 & 2.10 & 1.49 & $1 / 2$ & 91.1 & $10.7 / 89.3$ & 67.1 & 6.81 & 1.32 \\
\hline 7 & 7.07 & 1.13 & 2.10 & 1.49 & $1 / 2$ & 100.0 & $6.9 / 93.1$ & 99.5 & 8.35 & 1.19 \\
\hline 8 & 13.43 & 1.44 & 2.10 & 1.49 & $1 / 2$ & 93.6 & $5.3 / 94.7$ & 97.2 & 14.90 & 1.53 \\
\hline 9 & 6.04 & 1.27 & 3.42 & 1.43 & $1 / 2$ & 85.6 & $23.3 / 76.7$ & 65.7 & 8.07 & 2.14 \\
\hline 10 & 6.04 & 1.27 & 6.74 & 1.70 & $1 / 2$ & 69.1 & $41.5 / 58.5$ & 62.0 & 8.31 & 2.02 \\
\hline
\end{tabular}

${ }^{a}$ Run 3-6: $P_{1}$ and $P_{2}$ were added in equal molar ratio of the two end groups; Run 7-10: $P_{2}$ was added in excess. ${ }^{b}$ Number-average molecular weight and molecular weight distribution determined by SEC, calibrated by Polystyrene standards. ${ }^{\mathrm{c}}$ The molar ration of catalyst added and the end group of $\mathrm{P}_{1} .{ }^{\mathrm{d}}$ The yield of polymer precipitated from $\mathrm{MeOH}\left(\right.$ Run 3-5) or $n$-hexane(Run 1,2,6-10) based on the theoretical amount of block copolymer. ${ }^{\mathrm{e}}$ The molar ratio of VOTBDMS/CL in copolymer, evaluated by ${ }^{1} \mathrm{H}$ NMR. ${ }^{\mathrm{f}}$ Content of block copolymer determined by ${ }^{1} \mathrm{H}$ NMR, assuming that the DP of PCL block was unchanged after reaction.

and PVOTBDMS with different molecular weights as shown in Tables II and III were used.

As summarized in Table IV, the coupling reactions occurred in the presence of $\mathrm{ZnBr}_{2}$. In order to consider the influence of length of PCL-chain on the interaction with $\mathrm{ZnBr}_{2}$, PCL-OTMS with different molecular weights were reacted with $\mathrm{ZnBr}_{2}$ alone (Run 1, 2 in Table IV). It seems strange that the recovery yield of the polymer in the case of using short PCL-chain was lower than that for long PCL. It can be interpreted by the term of inter- and intramolecular transesterification caused by the interaction between $\mathrm{ZnBr}_{2}$ and oxygen atoms in PCL-chain. These reactions should bring about scrambling and formation of macrocycles ${ }^{25}$ respectively, as shown in the Scheme 3. The short PCLchain must give rather small size scrambling products soluble in $n$-hexane.

In fact, PCL with very low molecular weight was newly generated and could be isolated as the soluble part in $n$-hexane on the occasion of reprecipitation. This is the reason why the first recovery yield became
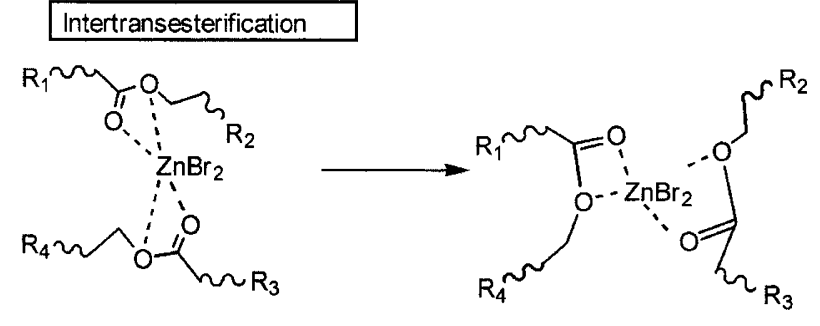

Intratransesterification

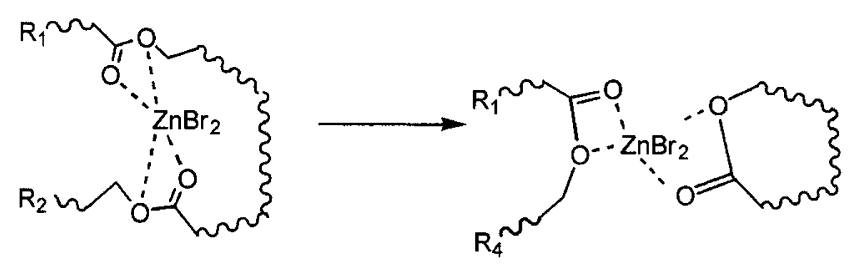

Scheme 3. Possible side reactions caused by the interaction of PCL-chain and $\mathrm{ZnBr}_{2}$.

low for Run 1. The use of PCL with relatively long chain (Run 2 in Table IV) showed little loss in recovery and no change in the molecular weight. This differ- 


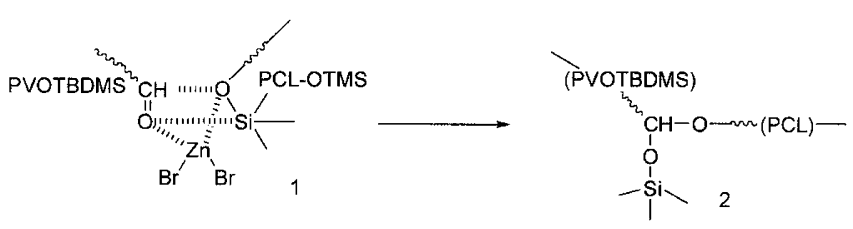

Scheme 4. The mechanism proposed to coupling reaction of PVOTBDMS and PCL-OTMS by using $\mathrm{ZnBr}_{2}$.

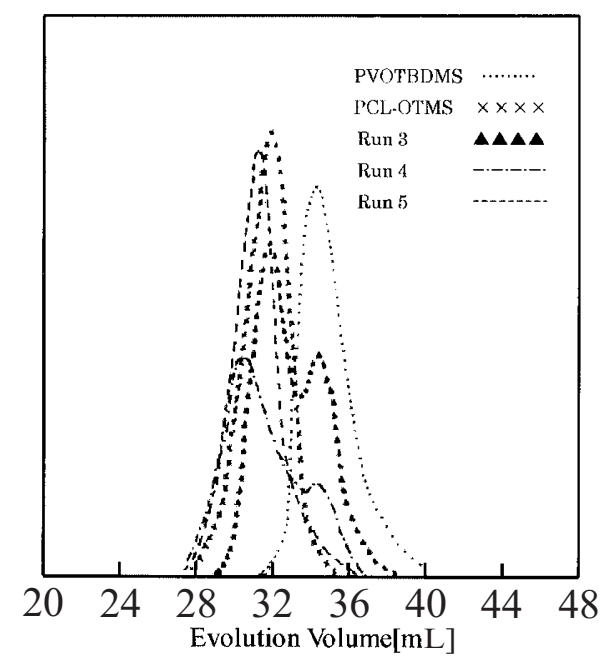

Figure 2. SEC charts monitored for Run 3-5 shown in Table IV.

ent behavior might be explained by the lowering Lewis acidity of $\mathrm{ZnBr}_{2}$ by the long PCL-chain, in other words, by the excess amounts of ester group.

It was assumed in the coupling system that $\mathrm{ZnBr}_{2}$ would be coordinated with both formyl end group of PVOTBDMS and trimethylsilyl end group of PCL and that a bicycle-type of transition state containing $\mathrm{ZnBr}_{2}$ would be formed, as is described in Scheme 4. This transition state is very similar to that proposed for initiation and propagation of Aldol-GTP and also the coupling reaction of PVOTBDMS prepared via Aldol-GTP with PMMA synthesized by Michael-GTP. ${ }^{21}$ Bond rearrangement and removing of the catalyst should result in the block copolymer designed in this work.

Methanol is a non-solvent for both PCL and PVOTBDMS and therefore was selected to precipitate coupling copolymers for Run 3-5 in Table IV, where two parent polymers were mixed in equal molar ratio with respect to the end group. The SEC charts monitored for Run 3,4 , and 5 are depicted in Figure 2. Judging from the unchanged bimodal SEC chart of the Run 3, coupling reaction could not occur in the absence of catalyst. In Run 4, the coupling reaction did not finish yet because of drawing still the bimodal SEC chart. In contrast with Run 4, the unimodal chart of Run 5 meant that the coupling reaction between the formyl group at the end of PVOTBDMS and the end group of PCL-OTMS proceeded completely. It seemed important to have in-
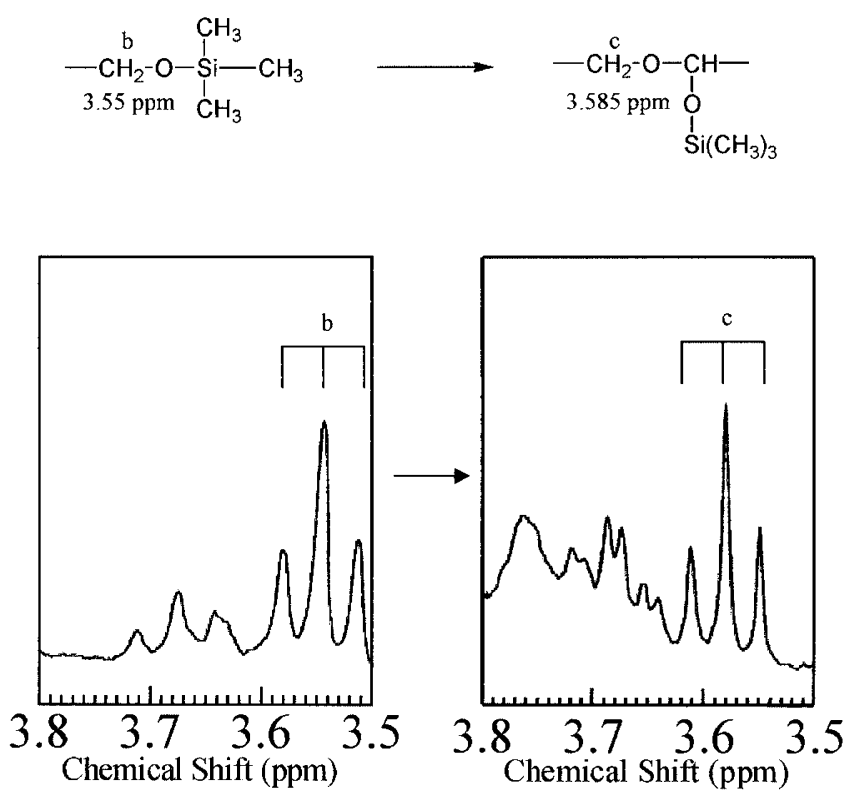

Figure 3. Monitoring of the chemical shift of $\mathrm{CH}_{2}$ proton adjacent to end group of PCL after coupling reaction of PVOTBDMS and PCL-OTMS.

creased the amount of catalyst up to about $30 \mathrm{~mol} \%$ to the end group of PCL-OTMS. Taking into account that the Lewis acidity of $\mathrm{ZnBr}_{2}$ must be lowered by the long PCL-chain, consequently the catalyst was added by $50 \mathrm{~mol} \%$ of the end group of PCL-OTMS in subsequent experiments (Run 6-10). As a result, the coupling copolymer was obtained in $c a$. $94 \%$ yield even for the PCL-OTMS with the molecular weight of $1.34 \times 10^{4}$ (Run 8). Although an equal molar ratio of parent polymers were mixed in Run 6, excess amounts of PVOTBDMS were added in Run 7 and 8. In this condition, the reaction proceeded to form completely the block copolymer independent of the chain length of PCLOTMS used. After the predetermined time, unreacted PVOTBDMS can be removed by precipitation with $n$ hexane (non-solvent). In the ${ }^{1} \mathrm{H}$ NMR spectrum of the polymer purified by reprecipitation from toluene solution into $n$-hexane, the signals assignable to the repeating structure of PCL- and PVOTBDMS-chain are observed, confirming the formation of the block copolymer just as designed. The composition of the coupled polymer can be calculated by the intensity of ${ }^{1} \mathrm{H}$ NMR peaks. The signal at $9.70 \mathrm{ppm}$ due to formyl end group in PVOTBDMS was disappeared, and the methylene proton adjacent to $-\mathrm{OSi}\left(\mathrm{CH}_{3}\right)_{3}$ of PCL was shifted from $3.55 \mathrm{ppm}$ to $3.585 \mathrm{ppm}$ with the coupling reaction progressed as shown in Figure 3. The corresponding SEC showed the unimodal chart and peak top shifted to higher molecular weight region, keeping narrow molecular weight distribution. These proofs support the occurrence of the reaction assumed in Scheme 4. By using a short PVOTBDMS-chain, the block copolymer 
Table V. Coupling reaction of TMS modified PCL $\left(\mathrm{P}_{1}\right)$ and PVOTBDMS $\left(\mathrm{P}_{2}\right)$ using $\mathrm{TiCl}_{4}$ as catalyst in toluene $\left(\mathrm{Tem} .=60^{\circ} \mathrm{C}\right.$, Time $\left.=150 \mathrm{~h}\right)$

\begin{tabular}{|c|c|c|c|c|c|c|c|c|c|c|}
\hline \multirow[b]{2}{*}{$\begin{array}{l}\text { Run } \\
\text { No. }{ }^{\text {a }}\end{array}$} & \multicolumn{2}{|c|}{$P_{1}$} & \multicolumn{2}{|c|}{$\mathrm{P}_{2}$} & \multirow{2}{*}{$\begin{array}{c}{\left[\mathrm{TiCl}_{4} /-\mathrm{OTMS}\right]^{\mathrm{c}}} \\
(\mathrm{mol} / \mathrm{mol})\end{array}$} & \multirow{2}{*}{$\begin{array}{l}\text { Yield }^{\mathrm{d}} \\
(\mathrm{wt} \%)\end{array}$} & \multirow{2}{*}{$\begin{array}{c}\mathrm{P}_{2} / \mathrm{P}_{1} \mathrm{e}^{-} \\
(\mathrm{mol} / \mathrm{mol})\end{array}$} & \multirow{2}{*}{$\begin{array}{c}\text { Block } \\
\text { copolymerf } \\
(\%) \\
\end{array}$} & \multirow{2}{*}{$\begin{array}{c}M_{\mathrm{n}}^{\mathrm{b}} \\
\times 10^{-3}\end{array}$} & \multirow[b]{2}{*}{$M_{\mathrm{w}} / M_{\mathrm{n}}$} \\
\hline & $\overline{M_{\mathrm{n}}}{ }^{\mathrm{b}}$ & $\begin{array}{l}M_{\mathrm{w}} / M_{\mathrm{n}} \mathrm{b} \\
0^{-3}\end{array}$ & $\overline{M_{\mathrm{n}}{ }^{\mathrm{b}}}$ & $\begin{array}{l}M_{\mathrm{w}} / M_{\mathrm{n}}^{\mathrm{b}} \\
10^{-3}\end{array}$ & & & & & & \\
\hline 1 & 2.40 & 1.31 & - & - & $1 / 3.5$ & 62.98 & - & - & 2.88 & 1.93 \\
\hline 2 & 6.04 & 1.27 & - & - & $1 / 3.5$ & 62.52 & - & - & 3.93 & 1.72 \\
\hline 3 & 2.40 & 1.31 & 2.10 & 1.49 & $1 / 10$ & 28.99 & $27.3 / 72.7$ & 72.80 & 7.16 & 2.53 \\
\hline 4 & 2.40 & 1.31 & 2.10 & 1.49 & $1 / 3.5$ & 53.40 & $25.7 / 74.3$ & 96.30 & 5.74 & 2.32 \\
\hline 5 & 6.04 & 1.27 & 2.10 & 1.49 & $1 / 3.5$ & 89.40 & $9.9 / 90.1$ & 80.70 & 7.33 & 1.93 \\
\hline 6 & 7.07 & 1.13 & 2.10 & 1.49 & $1 / 3.5$ & 85.60 & $9.3 / 90.7$ & 90.20 & 9.39 & 1.69 \\
\hline 7 & 13.43 & 1.44 & 2.10 & 1.49 & $1 / 3.5$ & 97.20 & $6.7 / 93.3$ & 100.00 & 16.70 & 1.56 \\
\hline 8 & 6.04 & 1.27 & 6.83 & 1.90 & $1 / 3.5$ & 67.00 & $37.3 / 62.3$ & 56.70 & 8.60 & 3.36 \\
\hline
\end{tabular}

${ }^{\mathrm{a}}$ Run 5: $\mathrm{P}_{1}$ and $\mathrm{P}_{2}$ were added in equal molar ratio of the two end groups; Run 3-4, 6-8: $\mathrm{P}_{2}$ was added in excess. ${ }^{b}$ Number-average molecular weight and molecular weight distribution determined by SEC , calibrated by Polystyrene standards. ${ }^{\mathrm{c}}$ The molar ratio of $\mathrm{TiCl}_{4}$ catalyst and the end group of $\mathrm{P}_{1}$. ${ }^{\mathrm{d}}$ The yield of polymer precipitated from $n$-hexane based on theoretical amount of block copolymer. ${ }^{\mathrm{e}} \mathrm{The}$ molar ratio of VOTBDMS/CL in copolymer precipitated from $n$-Hexane ,evaluated by ${ }^{1} \mathrm{H}$ NMR. ${ }^{\mathrm{f}}$ Content of block copolymer determined by ${ }^{1} \mathrm{H}$ NMR, assuming that the DP of PCL block was unchanged after reaction.

can be obtained nearly $100 \%$ independent of the chain length of PCL-OTMS used. The effect of PVOTBDMS with different molecular weights can be read in Table IV, too. The higher molecular weight of PVOTBDMS was used, the higher content of PVOTBDMS units can be apparently achieved in the crude polymer by means of ${ }^{1} \mathrm{H}$ NMR spectrum. However the content of a real block copolymer was decreased. The real block copolymer content was calculated on the assumption that the length of PCL-chain never changed during the coupling reaction. One reason for this decrease could be owing to the lowered diffusion ability of parent polymers. The long VOTBDMS- and PCLchain caused higher viscosity of the reaction mixture. The ${ }^{1} \mathrm{H}$ NMR analysis of the crude copolymer from Run 10 indicated that $77 \mathrm{wt} \%$ of the original PCL was involved intact. Based on the result of Run 2 (Table IV), there is no bad effect of $\mathrm{ZnBr}_{2}$ on the long PCL-chain. Since PVOTBDMS dissolves readily in $n$ hexane, the increasing content of PVOTBDMS unit in the real block copolymer must increase the solubility of copolymers in $n$-hexane. The block copolymer composed of long PVOTBDMS and short PCL chains will dissolve in $n$-hexane and cause somewhat the loss in yield as well as the content of real block copolymer after precipitation from $n$-hexane. Furthermore, it was confirmed by the signals assignable to PCL-chain in the ${ }^{1} \mathrm{H}$ NMR spectrum of supernatant from precipitation.

Then the coupling reactions in the presence of $\mathrm{TiCl}_{4}$ instead of $\mathrm{ZnBr}_{2}$ as catalyst were carried out and the results were summarized in Table $\mathrm{V}$. At first, the influence on the interaction of the PCL-chain with $\mathrm{TiCl}_{4}$ was investigated (Run 1,2 in Table V), comparing with $\mathrm{ZnBr}_{2}$ (Run 1,2 in Table IV). The recovered yield of PCL-
OTMS in Run 1 was in a similar level (63-66 wt\%) as the case of $\mathrm{ZnBr}_{2}$ catalyst, indicating the loss of small size compounds. The stronger Lewis acidity of $\mathrm{TiCl}_{4}$ than that of $\mathrm{ZnBr}_{2}$ made the molecular weight distribution $\left(M_{\mathrm{w}} / M_{\mathrm{n}}\right)$ broader. However, very different manner of $\mathrm{TiCl}_{4}$ from that of $\mathrm{ZnBr}_{2}$ was observed in the interaction of PCL with molecular weight of about 6000 (Run 2). The recovered polymer showed a new ${ }^{1} \mathrm{H}$ NMR signal at $11.5 \mathrm{ppm}$ assignable to carboxyl proton and its $M_{\mathrm{n}}$ lowered extremely and its $M_{\mathrm{w}} / M_{\mathrm{n}}$ index was increased up to 1.72 , suggesting that the random scission of PCL-chain still occurred extensively in spite of increasing amounts of ester groups. Large amounts of ester groups were not enough to suppress the acidity of $\mathrm{TiCl}_{4}$, on the contrary were useful to promote transesterification due to high concentration of ester groups. However, such change was never observed in the case of $\mathrm{ZnBr}_{2}$. After addition of PVOTBDMS, the interaction between $\mathrm{TiCl}_{4}$ and PCL-chain was weakened and the coupling reaction was expected to proceed according to the mechanism in Scheme 4, which was assumed for $\mathrm{ZnBr}_{2}$ catalyst. The SEC data showed an increase in molecular weight compared with that of parents. The side reaction with $\mathrm{TiCl}_{4}$ was responsible to the broadened molecular weight distribution as discussed above. Furthermore, the obvious signals assignable to both PCL- and PVOTBDMS-chains in ${ }^{1} \mathrm{H}$ NMR spectrum of the products gave a clear evidence for the formation of block copolymer. According to the results of Run 3 and 4 in Table V, content of the real block copolymer can be increased by increasing the amount of $\mathrm{TiCl}_{4}$, although it was sure to promote the side reaction, too. As compared with the results of Run 5 and 6 in Table V, it can be found that the yield of the real block copolymer will 
also be improved by addition of PVOTBDMS in excess. In the case of employing the long PCL-chain (Run 7, Table V), the side reactions due to $\mathrm{TiCl}_{4}$ seemed to be suppressed. This was reflected by the relatively small $M_{\mathrm{w}} / M_{\mathrm{n}}$ value of the coupled polymer and quantitative yield of the block copolymer.

On the contrary, the use of longer PVOTBDMSchain did not produce any good results in both the yield and the content of block copolymer (Run 8 in Table V). This effect has already observed in the case of $\mathrm{ZnBr}_{2}$ instead of $\mathrm{TiCl}_{4}$ as a catalyst and could be explained by the same reason.

\section{Desilylation of PCL-block-PVOTBDMS}

In order to obtain our final goal copolymer PCL-block-PVA, the preceding copolymer PCL-blockPVOTBDMS was treated with methanol as a proton source. Because of the higher chemical stability of tert-butyldimethysilyloxyl group, acid condition was required to promote the desilylation. It was very important to control the acidity of the system because the stronger acidity might lead to hydrolytic cleavage of PCL-chain besides the cleavage of $\mathrm{C}-\mathrm{O}-$ $\mathrm{SiR}_{3}$ linkage and even cleavage of the linking point of both block units in the worst case. Treatment of PCL-block-PVOTBDMS with methanol/trifluoroacetic acid(vol $1: 1$ ) mixture at $40^{\circ} \mathrm{C}$, which is a very usual condition for desilylation of VOTBDMS homopolymer, unfortunately resulted in not only the cleavage of $\mathrm{C}-\mathrm{O}-\mathrm{Si}$ bond but also the hydrolysis of ester groups. This could be confirmed by SEC, IR, and ${ }^{1} \mathrm{H}$ NMR data. On the other hand, treatment of the precursor copolymer with methanol containing a small amount of $\mathrm{HCl}$ (corresponded to only $8 \mathrm{~mol} \%$ of the total amount of silyl group in block copolymer) gave the polymer insoluble in good solvents for PCL including toluene, $\mathrm{CHCl}_{3}$, and THF, suggesting that the desilylation could take place smoothly according to our expectation. The PVA-chain length will decide the solubility of the block copolymer so long as side reaction was not occurred. This principle concerning to the solubility of related copolymers could be also applied to remove PCLOTMS which did not react in the coupling reaction and accidentally remained with the block copolymer after desilylation. The absorptions due to $\mathrm{Si}-\mathrm{CH}_{3}$ at 810 and $775 \mathrm{~cm}^{-1}$ in IR disappeared completely without any other significant change. In order to investigate the interaction of desilylation reagents on PCL-chain during the reaction, the homopolymer of CL was reacted under the same condition as the desilylation. The polymer could be recovered in $90 \mathrm{wt} \%$ yield even after reprecipitation from toluene into $n$-hexane. No change could be observed in its mean molecular weight as well as molecular weight distribution. Judging from this experiment, it was sure that the desilylation of PCL-blockPVOTBDMS by $\mathrm{MeOH}$ containing the small amounts of $\mathrm{HCl}$ was achieved successfully and resulted in PCLPVA block copolymer.

\section{CONCLUSION}

In this paper, we reported on successful synthesis of a novel biodegradable block copolymer, PCL-blockPVA, which is composed of both hydrophilic and hydrophobic units. The precursor block copolymer, PCLblock-PVOTBDMS, could be synthesized at first from coupling reaction of PVOTBDMS with TMSO-ended PCL by using $\mathrm{ZnBr}_{2}$ or $\mathrm{TiCl}_{4}$ as catalyst. Two starting polymers, PVOTBDMS and PCL, could be prepared by aldol-GTP and ring-opening polymerization of $\mathrm{CL}$, respectively, in a living manner. In the above coupling reaction, the relatively stronger Lewis acidity of $\mathrm{TiCl}_{4}$ gave rise to not only the coupling reaction but also the side reaction such as ester cleavage, and therefore made the $M_{\mathrm{w}} / M_{\mathrm{n}}$ values of the copolymers larger one. By using the longer PCL chain, the side reaction could be restrained. Under the optimum conditions, desilylation of PCL-block-PVOTBDMS with methanol-HCL resulted in the target block copolymer without any wrong effects, for example the hydrolytic cleavage of PCL-chain. Biodegradability of these new block copolymers and other properties would be dependent on the balance of chain length of PVA and PCL units.

\section{REFERENCES}

1. Y. Ikada, "Basics and application of biodegradable Polymers", IPC Publishers, Tokyo, 1999.

2. Y. Inoue and N. Yoshie, Prog. Polym. Sci., 17, 571 (1992).

3. Y. Doi, "Microbial Polyesters", VCH Publishers, New York, N.Y., 1990.

4. T. U. Gerngross and S. C. Slater, Scient. Am., 37 (2000).

5. A. Cao, T. Okamura, C. Ishiguro, K. Nakayama, Y. Inoue, and T. Masuda, Polymer, 43, 671 (2002).

6. Y. Maeda, A. Nakayama, N. Kawazalo, K. Hayashi, S. Aiba, and N. Yamamoto, Polymer, 38, 4719 (1997).

7. Z. Jedliski, P. Kurcok, and R. W. Lenz, J. Macromol. Sci., Pure Appl. Chem., A32, 797 (1995).

8. Y. Q. Shen, Z. Q. Shen, Y. F. Zhang, and K. M. Yao, Macromolecules, 29, 8289 (1996).

9. J. Dahlman and G. Rafler, Acta Polym., 43, 91 (1992).

10. H. R. Kricheldorf, S. R. Lee, and S. Bush, Macromolecules, 29, 1375 (1996).

11. P. J. A. In't Veld, E. M. Velner, P. Van De Witte, J. Hamhuis, P. J. Dijkstra, and J. Feijen, J. Polym. Sci., Part A: Polym. Chem., 35, 219 (1997).

12. D. Mecerreyes, R. Jerôme, and P. Dubois, Adv. Polym. Sci., 
147, 1 (1999).

13. a) S. Kobayashi, Synlett, 689 (1994). b) D. Longbottom, Synlett, 2023 (1999).

14. N. Nomura, A. Taira, and M. Okada, Macromolecules 33, 1497 (2000).

15. M. Möller, R. Kånge, and J. L. Hedrick, J. Polym. Sci., Part A: Polym. Chem., 38, 2067 (2000).

16. B. Parrish, J. K. Quansah, and T. Emrick, J. Polym. Sci., Part A: Polym. Chem., 40, 1983 (2002).

17. K. Kasuya, K. Takaki, S. I. Ishiwatari, Y. Yoshida, and Y. Doi, Polym. Degrad. Stab., 59, 327 (1998).

18. A. Misra and S. N. Garg, J. Polym. Sci., Polym. Phys., 24, 999 (1986).
19. S. Gartiser, M. Wakkrabestein, and G. Stiene, J. Environ. Polym. Degrad., 6, 159 (1999).

20. C. De Kesel, C. Lefèvre, J. B. Nagy, and C. David, Polymer, 40, 1969 (1999).

21. D. Y. Sogah and O. W. Webster, Macromolecules, 19, 1775 (1986).

22. M. E. Jung and R. B. Blum, Tetrahedron Lett., 43, 3791 (1977).

23. A. Schindler, Y. M. Hibionada, and C. G. Litt, J. Polym. Sci., Part A: Polym. Chem., 20, 319 (1982).

24. S. Penczek and A. Duda, Macromol. Symp., 107, 1 (1996).

25. A. Semma, M. Christian, D. Kurt, and G. Andreas, Macromol. Rapid Commun., 21, 195 (2000). 